\title{
A Three-Dimensional Algebraic Grid Generation Scheme for Gas Turbine Combustors With Inclined Slots
}

S.L. Yang

Michigan Technological University

Houghton, Michigan

M.C. Cline

Los Alamos National Laboratory

Los Alamos, New Mexico

and

R. Chen and Y.L. Chang

Michigan Technological University

Houghton, Michigan.

March 1993

Prepared for

Lewis Research Center

Under Grant NAG3-1109 
$\therefore=$

-

-

- 


\title{
A THREE-DIMENSIONAL ALGEBRAIC GRID GENERATION SCHEME FOR GAS TURBINE COMBUSTORS WITH INCLINED SLOTS
}

\author{
S. L. Yang ${ }^{1}$ \\ ME-EM Department \\ Michigan Technological University \\ Houghton, Michigan 49931 \\ M. C. Cline \\ Los Alamos National Laboratory \\ Los Alamos, New Mexico \\ R. Chen ${ }^{2}$ and Y.-L. Chang ${ }^{2}$ \\ ME-EM Department \\ Michigan Technological University
}

\begin{abstract}
A 3D algebraic grid generation scheme is presented for generating the grid points inside gas turbine combustors with inclined slots. The scheme is based on the 2D transfinite interpolation method. Since the scheme is a 2D approach, it is very efficient and can easily be extended to gas turbine combustors with either dilution hole or slot configurations.

To demonstrate the feasibility and the usefulness of the technique, a numerical study of the quick-quench/lean-combustion (QQ/LC) zones of a staged turbine combustor is given. Preliminary results illustrate some of the major features of the flow and temperature fields in the $\mathrm{QQ} / \mathrm{LC}$ zones. Formation of co- and counter-rotating bulk flow and sandwiched-ring-shape temperature fields can be observed clearly, and the resulting patterns are consistent with experimental observations typical
\end{abstract}

1 Assistant Professor, to whom correspondence should be addressed.

2 Graduate Research Assistant 
of the confined slanted jet-in-cross flow. Numerical solutions show the method to be an efficient and reliable tool for generating computational grids for analyzing gas turbine combustors with slanted slots. 


\section{INTRODUCTION}

The current issue of environmental pollution imposes an urgent need in the reduction of NOx emissions from gas turbine engines. One way to reduce such NOx emissions is to use the staged turbine combustor (STC) concept [1-4]. One STC combustor is schematically shown in Figure 1. It consists of a fuel nozzle (FN), a rich-burn (RB) zone, a converging pipe, a quick-quench (QQ) zone, a diverging pipe, and a lean-combustion (LC) zone.

There are basically two approaches for modeling chemically reactive fluid flow and heat transfer phenomena in the STC combustor shown in Figure 1. The first is to consider the whole combustor as a single unit. The second is to isolate each zone and then connect them through inlet/outlet boundary conditions. This allows the zones to be treated differently. For example, the FN/RB zone can be assumed to be axisymmetric (with swirl), while the QQ/LC zones must be modeled in three-dimensional (3D) due to the jet-in-cross flow. From computational efficiency view point, the second approach is preferred and was used in our approach [5-7] in which the FN/RB zone was calculated as an axisymmetric problem with a finer mesh to resolve the airblast nozzle passage flow fields $[5,6]$ and the $\mathrm{QQ} / \mathrm{LC}$ zones was modeled as a 3D problem using a coarser sector mesh to isolate one slot $[5,7]$.

The purpose of this paper is to present an algebraic 3D grid generation scheme for gas turbine combustors with inclined slots. The method used to generate the grids is based on the 2D transfinite interpolation (TI) method [8-11]. Since the scheme is a 2D approach, it is very efficient and can easily be extended to gas turbine combustors with either dilution hole or slot configurations. 
To demonstrate the feasibility and the usefulness of the approach just outlined, numerical solutions for the chemically reactive flow and heat transfer fields inside the $Q Q / L C$ zones of the STC are obtained using a modified version of the KIVA-II code [12]. Input conditions are chosen to be similar to those encountered in advanced combustion systems.

\section{DESCRIPTION OF PROBLEM}

We will focus on the QQ/LC region of the STC combustor shown in Figure 1. In this region, cool dilution air is injected into the $\mathrm{QQ}$ zone through slanted slots. In the model, to minimize the effect of the inter-zone boundary conditions, the inlet boundary is extended 3 inches upstream of the convergence section (see Figure 1 for the FN/RB zone and QQ/LC zones computational sections). Likewise, to avoid flow contamination due to outflow boundary conditions, the LC zone is extended 6.6 inches downstream of the divergence section. Figure 2 shows the geometry of the QQ/LC zones. In this figure, $\mathrm{D}$ and $\mathrm{L}_{\text {quick }}$ are the diameter and the length of the $\mathrm{QQ}$ zone, respectively.

There are equally-spaced inclined slots located around the perimeter of the $Q Q$ zone. The center of the slots is located at $D / 3$ downstream of the inlet of the $Q Q$ zone. The slot opening area is determined such that the jet-to-mainstream mass flow rate ratio is a chosen constant with a predetermined slot orifice discharge coefficient. Due to geometric symmetry, only one slot is modeled resulting in a sector as shown in section AA of Figure 2, in which the sector angle is $45^{\circ}$ for a 8 slots configuration. The slot is symmetrically located at the center plane of the sector.

\section{THE GRID GENERATION SCHEME}

In this section, the 2D TI method will be briefly reviewed first. The generation of the 3D mesh for the $\mathrm{QQ} / \mathrm{LC}$ region with inclined slots is then given. 


\section{The Transfinite Interpolation Method}

Following Gordon and Hall [8], consider a 2D region as shown in Figure 3 represented by a vector-valued function $\vec{F}$ which is covered by a normalized parametric coordinate system in $\xi$ and $\eta$. Accordingly, the corresponding transformation plane $(\xi-\eta$ plane) is a square region. There are two sets of constraint curves embedded in $\vec{F}$. One set has $M$ constraint curves (solid lines) denoted by $\vec{F}\left(\xi_{\mathrm{k}}, \eta\right)$, where $\mathrm{k}=1,2, \ldots, \mathrm{M}, \xi_{1}=0$, and $\xi_{\mathrm{M}}=1$. The other set has $\mathrm{N}$ constraint curves (dashed lines) and is denoted by $\vec{F}\left(\xi, \eta_{j}\right)$, where $\mathrm{j}=1,2, \ldots, \mathrm{N}, \eta_{1}=0$, and $\eta_{N}=1$. The Boolean sum projector or transfinite interpolant, which matches $\vec{F}$ exactly along each of the $\mathrm{M}+\mathrm{N}$ constraint curves, is constructed as follows [8]:

$$
\left(\mathcal{P}_{\xi} \oplus \mathcal{P}_{\eta}\right)[\vec{F}]=\mathcal{P}_{\xi}[\vec{F}]+\mathcal{P}_{\eta}[\vec{F}]-\mathcal{P}_{\xi} \mathcal{P}_{\eta}[\vec{F}]
$$

where the transformation projectors, $\mathcal{P}_{\xi}$ and $\mathcal{P}_{\eta}$ are defined in terms of blending functions $\phi$ and $\psi$

as

$$
\begin{array}{ll}
\mathcal{P}_{\xi}[\vec{F}]=\sum_{k=1}^{M} \phi_{k}(\xi) \vec{F}\left(\xi_{k}, \eta\right), & 0 \leq \eta \leq 1 \\
\mathcal{P}_{\eta}[\vec{F}]=\sum_{j=1}^{N} \Psi_{j}(\eta) \vec{F}\left(\xi, \eta_{j}\right), & 0 \leq \xi \leq 1
\end{array}
$$

and the product projection which matches $\vec{F}$ at the intersections of the two sets of constraint curves is defined by

$$
\mathcal{P}_{\xi} \mathcal{P}_{\eta}[\vec{F}]=\sum_{k=1}^{M} \sum_{j=1}^{N} \phi_{k}(\xi) \psi_{j}(\eta) \vec{F}\left(\xi_{k}, \eta_{j}\right)
$$

In the above equations, the blending functions, $\phi$ and $\psi$, are expressed as: 


$$
\begin{gathered}
\phi_{k}(\xi)=\frac{\prod_{\substack{m=1 \\
m \neq k}}^{M}\left(\xi-\Phi_{m}\right)}{\prod_{\substack{m=1 \\
m \neq k}}^{M}\left(\Phi_{k}-\Phi_{m}\right)}, \quad k=1,2, \ldots, M \\
\Psi_{j}(\eta)=\frac{\prod_{\substack{n=1 \\
n \neq j}}^{N}\left(\eta-\Psi_{n}\right)}{\prod_{\substack{n=1 \\
n \neq j}}^{N}\left(\Psi_{j}-\Psi_{n}\right)}, \quad j=1,2, \ldots, N
\end{gathered}
$$

where the coefficients $\Phi$ and $\Psi$ are defined by

$$
\begin{aligned}
& \Phi_{k}=\sum_{m=1}^{M} \frac{k\left(\xi_{m}\right)-1}{k m a x-1} \\
& \Psi_{j}=\sum_{n=1}^{N} \frac{j\left(\eta_{n}\right)-1}{j \max -1}
\end{aligned}
$$

Here kmax and jmax are the total number of grid lines in the respective $\xi$ and $\eta$ directions. $k\left(\xi_{m}\right)$ and $j\left(\eta_{n}\right)$ are functions giving the $k$ and $j$ indices of the constraint curves, respectively.

Equation (1) approximates $\vec{F}$ in the sense that it describes an approximate domain matching $\vec{F}$ on the non-denumerable (transfinite) set of points comprising the $\mathrm{M}+\mathrm{N}$ constraint curves [8].

\section{Application to the Combustors with Inclined Slots}

To facilitate the grid generation scheme using the TI method described above, the QQ/LC computational region shown in Figure 2 is divided into three subdomains: the RB zone together with the convergence section, the QQ zone with slot, and the divergence section along with the LC zone. The TI method is first applied to the $\mathrm{QQ}$ zone with grid lines exactly describing the desired 
slot geometry, but with zero inclination angle. Next, the TI method is applied to the other two subdomains but with grids generated only for one $r-z$ plane. A patching procedure is then used to generate the grid lines in the azimuthal $(\theta)$ direction, based on the previously generated $Q Q$ zone 3D grid. The final step is to twist the mesh by the desired angle, i.e., the slanted slot angle, to form the inclined slot configuration. Following is a more detailed description of the grid generation procedure.

Referring to Figure 4(a), first, a rectangular " $z-p$ " plane is formed by linearly connecting two points at the beginning and the end of the $\mathrm{QQ}$ zone. The slot is then projected from the curved combustor wall onto this z-p plane. Figure 4(b) shows the outcome of these steps. The parametric equations describing the four boundaries of the z-p plane shown in Figure 4(b) are

$$
\begin{array}{ll}
z\left(\xi, \eta_{1}\right)=\left(z_{f}-z_{i}\right) \xi+z_{i}, & p\left(\xi, \eta_{1}\right)=p_{i} \\
z\left(\xi, \eta_{4}\right)=\left(z_{f}-z_{i}\right) \xi+z_{i}, & p\left(\xi, \eta_{4}\right)=p_{f} \\
z\left(\xi_{1}, \eta\right)=z_{i}, & p\left(\xi_{1}, \eta\right)=\left(p_{f}-p_{i}\right) \eta+p_{i} \\
z\left(\xi_{4}, \eta\right)=z_{f}, & p\left(\xi_{4}, \eta\right)=\left(p_{f}-p_{i}\right) \eta+p_{i} .
\end{array}
$$

The equations for the lines describing the slot boundaries are

$$
\begin{array}{ll}
z\left(\xi, \eta_{2}\right)=\left(z_{f}-z_{i}\right) \xi+z_{i}, & p\left(\xi, \eta_{2}\right)=p_{c}-0.5 S_{W} \\
z\left(\xi, \eta_{3}\right)=\left(z_{f}-z_{i}\right) \xi+z_{i}, & p\left(\xi, \eta_{3}\right)=p_{c}+0.5 S_{W} \\
z\left(\xi_{2}, \eta\right)=z_{c}-0.5 S_{L}, & p\left(\xi_{2}, \eta\right)=\left(p_{f}-p_{i}\right) \eta+p_{i} \\
z\left(\xi_{3}, \eta\right)=z_{c}+0.5 S_{L}, & p\left(\xi_{3}, \eta\right)=\left(p_{f}-p_{i}\right) \eta+p_{i}
\end{array}
$$

where $z_{c}$ and $p_{c}$ are the slot center coordinates and $S_{W}$ and $S_{L}$ are the modified slot width $(W)$ and length $(L)$, respectively, given by 


$$
S_{W}=\frac{W}{\cos \theta_{\text {slot }}}, \quad S_{L}=L \cdot \cos \theta_{\text {slot }}
$$

Here $\theta_{\text {slot }}$ is the slot inclination angle. $\xi$ and $\eta$ in Eqns (9)-(16) are the normalized parametric coordinates, $0 \leq \xi, \eta \leq 1$, and defined by

$$
\begin{array}{ll}
\xi=\frac{z-z_{i}}{z_{f}-z_{i}}, & z_{i} \leq z \leq z_{f} \\
\eta=\frac{p-p_{i}}{p_{f}-p_{i}}, & p_{i} \leq p \leq p_{f}
\end{array}
$$

These are the two sets of the constraint curves (M=4 and $N=4)$ used in Eq (1) to generate the mesh shown in Figure 5, i.e., Eqns (11), (12), (15), and (16) form one set of the M constraint curves and, Eqns (9), (10), (13), and (14) form the other set. The input data for generating Figure 5 are given in Table 1 in which $\theta_{\text {secior }}$ is the sector angle. Note that a cubic polynomial stretching function [13] is used to space the grid points in the $\xi$ direction so that the grid spacing gradually changes away from the slot as shown in Figure 5.

Table 1: Grid Data for Figure 5

\begin{tabular}{|c|c|c|c|c|c|c|}
\hline $\mathrm{kmax}=22$ & $\mathrm{k}\left(\xi_{1}\right)=1$ & $\mathrm{k}\left(\xi_{2}\right)=3$ & $\mathrm{k}\left(\xi_{3}\right)=16$ & $\mathrm{k}\left(\xi_{4}\right)=22$ & $\mathrm{z}_{\mathrm{i}}=0$ & $\mathrm{z}_{\mathrm{f}}=\mathrm{D}$ \\
\hline $\mathrm{jmax}=19$ & $\mathrm{i}\left(\eta_{1}\right)=1$ & $\mathrm{i}\left(\eta_{2}\right)=8$ & $\mathrm{i}\left(\eta_{3}\right)=12$ & $\mathrm{i}\left(\eta_{4}\right)=19$ & $\mathrm{p}_{\mathrm{i}}=0$ & $\mathrm{p}_{\mathrm{f}}=\left[\frac{D^{2}}{2}\left(1-\cos \theta_{\text {sector }}\right)\right]^{1 / 2}$ \\
\hline
\end{tabular}


With the z-p plane grid defined, an inverse procedure is carried out to project grid points back to the combustor wall (See Figure 6). Accordingly, the $\mathrm{x}$ and $\mathrm{y}$ coordinates of the grid points on the combustor wall must satisfy the following two equations simultaneously

$$
\begin{aligned}
& x_{i \max , j, k}^{2}+y_{i \max , j, k}^{2}=\left(\frac{D}{2}\right)^{2} \\
& y_{\text {imax }, j, k}=C_{1}+C_{2} x_{i \max , j, k} \quad 1 \leq j \leq j \max ; \quad 1 \leq k \leq k \max
\end{aligned}
$$

where imax is the $\mathrm{i}$ index on the combustor wall and equals the total number of radial grid points. The coefficients $C_{1}$ and $C_{2}$ in Eq (19) for each point are determined such that the projection line is normal to the z-p plane at the point of intersection. The z-coordinate on the combustor wall is simply the z-coordinate on the z-p plane. From Eq (19), $\theta$ for each point on the combustor wall is determined by:

$$
\theta_{i \max , j, k}=\tan ^{-1}\left(\frac{y_{i \max , j, k}}{x_{i \max , j, k}}\right)
$$

To obtain the $x-, y-$, and $z$-coordinates of grid points at the other radial planes, i.e., $0 \leq r<D / 2$, the following equations are used

$$
\begin{aligned}
& x_{i, j, k}=r_{i, j, k} \cos \theta_{i \max , j, k} \\
& y_{i, j, k}=r_{i, j, k} \sin \theta_{i \max , j, k} \\
& z_{i, j, k}=z_{i \max , j, k}
\end{aligned}
$$

where $\mathrm{r}_{\mathrm{i}, \mathrm{j}, \mathrm{k}}$ is calculated as follows: 


$$
\begin{array}{ll}
r_{\text {imax }, j, k}=\frac{D}{2} & \\
r_{i, j, k}=r_{i+1, j, k}-\Delta r_{i} & 1 \leq i<i \max
\end{array}
$$

Here $\Delta r_{i}$ is the grid spacing in the radial direction.

This completes the description of the grid generation for the $\mathrm{QQ}$ zone with zero slot inclination angle. In the case of non-rectangular slot configurations, e.g., circular holes, Eqns (13)-(16) need to be modified accordingly.

To generate grids for the $\mathrm{RB} /$ convergence section, one $\mathrm{r}-\mathrm{z}$ plane with $\theta$ equal to 0 is used. Figure 7(a) shows the location and geometry of the appropriate embedded constraint curves, $M$ of 3 and $\mathrm{N}$ of 2 in this case. The TI method is then used to generate the mesh for this plane with one grid line exactly following the combustor wall in the convergence section. To obtain the grid for $\theta$ not equal to 0 , a patching procedure is used to match the previously generated $Q Q$ zone $3 \mathrm{D}$ grid. Similar procedures are carried out for the divergence/LC section. Figure $7(b)$ shows the embedded constraint curves ( $M=3, N=2)$ for this section.

A perspective view of the grid at this point in the analysis is shown in Figure 8. Figure 9 shows typical $r-\theta$ and $r-z$ planar views of the mesh in Figure 8 . There were 21 points in the r-direction, 19 points in the $\theta$-direction, and 53 points in the $z$-direction.

To modify the grid to account for a slanted slot, the mesh is twisted by the desired slot inclination angle, $\theta_{\text {slor }}$, about the centerline and a reference base plane ( $r-\theta$ plane). The following transformation equations then result: 


$$
\begin{array}{ll}
\text { xnew }_{i, j, k}=x_{i, j, k} \cos \Theta_{k}-y_{i, j, k} \sin \Theta_{k} & \\
\text { ynew }_{i, j, k}=x_{i, j, k} \sin \Theta_{k}+y_{i, j, k} \cos \Theta_{k} & \\
\text { znew }_{i, j, k}=z_{i, j, k} & 1<i \leq \text { imax } ; 1 \leq j \leq j \max
\end{array}
$$

where $\Theta_{k}$ is the $k^{\text {th }}$ plane twisting angle, relative to the $(\mathrm{k}-1)^{\text {th }}$ plane, and is defined by:

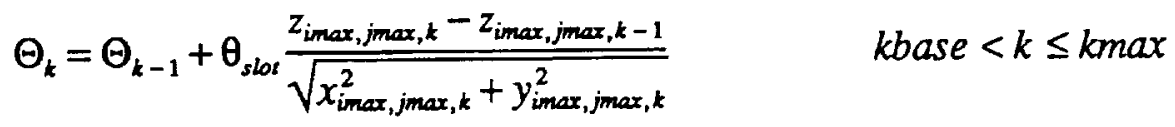

Here kbase is the $\mathrm{k}$ index of the base plane which is a fixed plane, i.e., $\Theta_{\mathrm{kbase}}=0$.

Figure 10 shows a perspective view of the grid generated with $\theta_{\text {slot }}$ of $45^{\circ}$ in which the reference base plane is taken as the inlet plane of the QQ zone (i.e. the last plane of the convergence section).

\section{APPLICATIONS}

To see the effect of the twisted mesh on the solutions, a pure pipe flow with uniform inlet and without swirl was analyzed for the grid system with and without grid twisting. It was found that the nonphysical swirl induced by the twisted mesh was less than $1 \%$ and, thus, could be considered insignificant. The approach was therefore considered appropriate for application to more realistic problems. The mesh shown in Figure 10 was used for the numerical solutions to be presented next.

A 3D analysis of the reacting flow and heat transfer inside the QQ/LC zones was studied using a modified version of the KIVA-II code and the grid-generation scheme developed here. Only a brief description is given here to facilitate the interpretation of the results; however, complete details can be found in [5-7]. 
In the problem considered, a hot rich mixture from the $\mathrm{RB}$ zone enters the $\mathrm{QQ}$ section with inlet conditions obtained from the study described in $[5,6]$. There are 8 equally-spaced $45^{\circ}$ slanted slots with slot aspect ratio (L/W) of 12 around the QQ zone, resulting in $\theta_{\text {seator }}$ of $45^{\circ}$. The jet-to-mainstream mass flow rate and momentum flux ratios are 3 and 60 , respectively, and the slot discharge coefficient is 0.6 . At the slot, the dilution jet is air (consisting of $76.8 \%$ of $\mathrm{N}_{2}$ and $23.2 \%$ of $\mathrm{O}_{2}$ ) which enters through the slanted slot with uniform radial velocity. The following jet inflow conditions are used:

$$
\begin{aligned}
& \text { Temperature }=1000^{\circ} \mathrm{F}\left(811^{\circ} \mathrm{K}\right) \\
& \text { Pressure }=90 \text { psia }\left(6.205 \times 10^{6} \mathrm{dynes} / \mathrm{cm}^{2}\right) \\
& \text { Turbulence intensity }\left(\mathrm{v}^{\prime}\right)=0.1 \text { of } \mathrm{V} \\
& \text { Turbulence length scale }=0.13 \text { of } \mathrm{D}
\end{aligned}
$$

where $\mathrm{V}$ is the jet inflow radial mean speed.

Figure 11 shows the computed isotherms and velocity vectors at the inlet plane which were taken from the study of the RB zone calculation $[5,6]$. Isotherms and velocity vectors at the center plane of the slot are given in Figure 12. Due to the slanted slot, neither the two vortices which form on both sides of the jet nor the isotherms are symmetrical with respect to the jet. It can be seen that near the wall the high velocity dilution jet deflects the main flow, causing swirl rotating in the direction parallel to the slot. However, near the axis, the main flow deflects the dilution jet, setting up a counter-rotating swirl in the direction of the main flow.

The interaction of the inclined jet with the main flow is the cause of the co- and counter-rotating bulk flow patterns shown in Figure 13 (isotherms are also given). This is the plane located about 0.991 inches $(2.517 \mathrm{~cm})$ downstream of the slot center. From Figure 13, we see there is a high 
shear layer (HSL) located near the mid-radius of the sector. The isotherms plot indicates that the HSL mainly contains lower temperature fluid, an indication of the effect of the jet penetration. The sandwiched-ring-shape (for a whole circle) temperature field, in the order of hot-cold-hot, can also be seen clearly in Figure 13. This bulk swirl flow and the sandwiched-ring-shape isotherm patterns, which are typical of confined slanted jet-in-cross flow, have been observed experimentally [14].

The bulk swirl flow persists further downstream, as shown in Figures 14 and 15. From these two figures, one can see that the HSL is moving outward radially before entering the divergence section, see Figure 14. However, at the end of the divergence section (Figure 15), the HSL is shifting toward the axis (radially inward).

At the exit of the LC zone, the bulk flow has almost disappeared and the fluid temperature is in the range of 1060 to $1340 \mathrm{~K}$, see Figure 16. A simple one-dimensional analysis (Figure 17) will show that, with the given input conditions, the outlet equilibrium temperature should be approximately $1208 \mathrm{~K}$.

\section{CONCLUSIONS}

We have presented an efficient algebraic grid generation scheme based on a 2D transfinite interpolation technique to generate the 3D grid for gas turbine combustors with slanted slots. This scheme can easily be extended to gas turbine combustors with slot or other dilution hole geometries.

Todemonstrate the feasibility and the usefulness of the technique, it was applied to the analysis of the QQ/LC zones of an STC combustor. It was found that the fictitious swirl induced by the twisted mesh was less than $1 \%$ and, thus, could be considered insignificant. Major features of the flow and temperature fields taking place inside the QQ/LC zones were satisfactorily modeled. 
Formation of the co- and counter-rotating bulk flow patterns and the sandwiched-ring-shape temperature field that occurs in the model can be seen clearly, which is consistent with experimental observations.

Numerical solutions show that the method presented can be used as a tool to generate the grid points for gas turbine combustors with slanted slots.

\section{ACKNOWLEDGEMENTS}

The authors wish to thank NASA LeRC for funding this work under NASA Contracts NAG3-1109 and C-30050-R. Our thanks are also extended to T. Daniel Butler, Anthony A. Amsden and Peter J. O'Rourke of the Los Alamos National Laboratory for all their help with the KIVA-II code. 


\section{REFERENCES}

1. Novick, A. S. and Troth, D. L., "Low NOx Heavy Fuel Combustor Concept Program," NASA CR-165367, 1981.

2. Lew, H. G., Carl, D. R., Vermes, G., DeZubay, E. A., Schwab, J. A., and Prothroe, D., "Low NOx Heavy Fuel Combustor Concept Program, Phase I: Combustion Technology Generation Final Report," NASA CR-165482, 1981.

3. Pierce, R. M., Smith, C. E., and Hinton, B. S., "Low NOx Combustor Development for Stationary Gas Turbine Engines," Proc. of the 3rd Stationary Source Combustion Symposium, EPA-600/7-79-050C, Vol. 3, February, 1979.

4. Kemp, F. S., Sederquist, R. A., and Rosfjord, T. J., "Evaluation of Synthetic Fuel Character Effects on Rich-Lean Stationary Gas Turbine Combustion Systems," Vol. 1 \& 2, EPRI AP-2822, Project 1898-1, Final Report, February 1983.

5. Yang, S. L., Chen, R., Cline, M. C., Nguyen, H. L., and Micklow, G. J., "Numerical Simulation of a Low Emissions Gas Turbine Combustor Using KIVA-П," Submitted to the Intermational Journal of Numerical Methods in Fluids, 1992.

6. Yang, S. L., Chen, R., Cline, M. C., Nguyen, H. L., and Micklow, G. J., "Numerical Simulation of Low Emissions Gas Turbine Combustor Using KIVA-II, Part I: Rich Zone Analysis," to be published as a NASA TM report, 1992.

7. Yang, S. L., R. Chen, Cline, M. C., and Nguyen, H. L., "Numerical Simulation of Low Emissions Gas Turbine Combustor Using KIVA-II, Part II: Quick-Quench/Lean-Combustion Zones Analysis," to be published as a NASA TM report, 1992. 
8. Gordon, W. J. and Hall, C. A., "Construction of Curvilinear Co-ordinate Systems and Applications to Mesh Generation," International Journal for Numerical Methods in Engineering, Vol. 7, pp. 461-477, 1973.

9. Hall, C. A., "Transfinite Interpolation and Applications to Engineering Problems," in the Theory of Approximation, Law and Sahney, Editors., Academic Press, pp. 308-331, 1976.

10. Haber, R., Shephard, M. S., Abel, J. F., Gallagher, R. H., and Greenberg, D. P., "A General Two-Dimensional, Graphical Finite Element Preprocessor Utilizing Discrete Transfinite Mappings," International Journal for Numerical Methods in Engineering, Vol. 17, pp. 1015-1044, 1981.

11. Haber, R. and Abel, J. F., "Discrete Transfinite Mappings for the Description and Meshing of Three-Dimensional Surfaces Using Interactive Computer Graphics," International Journal for Numerical Methods in Engineering, Vol. 18, pp. 41-66, 1982.

12. Amsden, A. A., O'Rourke, P. J., and Butler, T. D., "KIVA-II: A Computer Program for Chemically Reactive Flows with Spray," LA-11560-MS, UC-96, Los Alamos National Laboratory, May, 1989

13. Yang, S. L., "Fluid Flow and Heat Transfer in a Single-Pass, Return-Flow Heat Exchanger," Ph.D. Thesis, University of Florida, Gainesville, Florida, 1985.

14. Winowich, N. S., Moeykens, S. A., and Nguyen, H. L., "Three-Dimensional Calculation of the Mixing of Radial Jets from Slanted Slots with a Reactive Cylinderical Crossflow," AIAA-91-2081, AIAA/SAE/ASME/ASEE 27th Joint Propulsion Conference, 1991. 


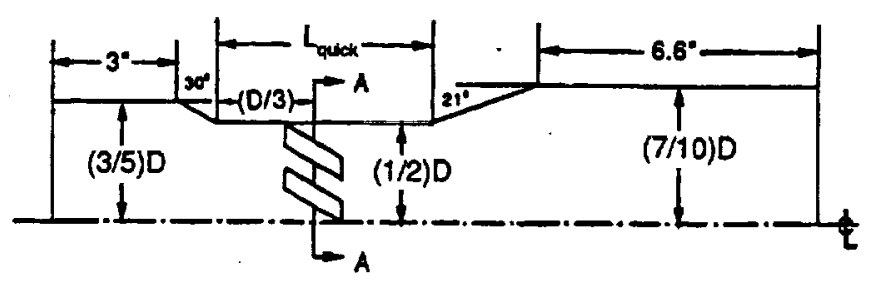

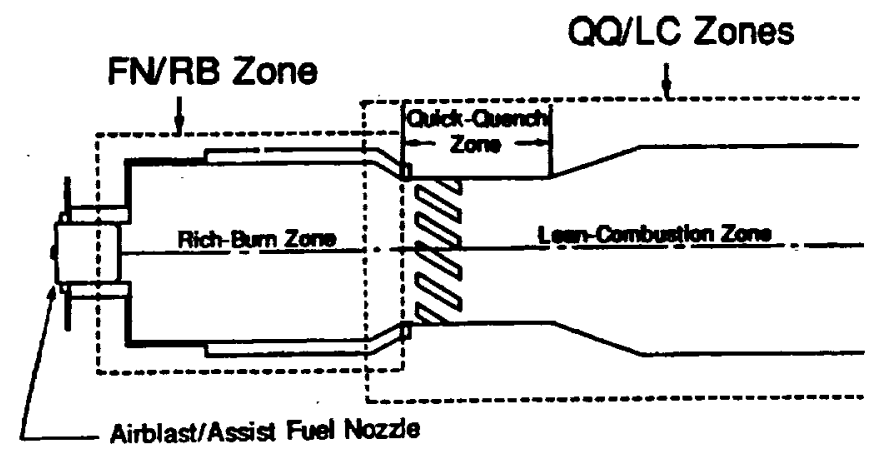

Figure 1. Schematic of a staged turbine Combustors.

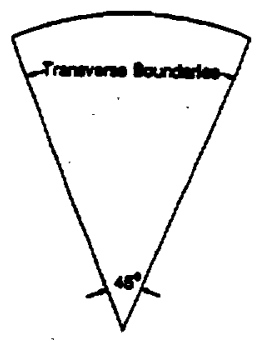

Section AA

Figure 2.-Geometry of the system under investigation and its specifications.

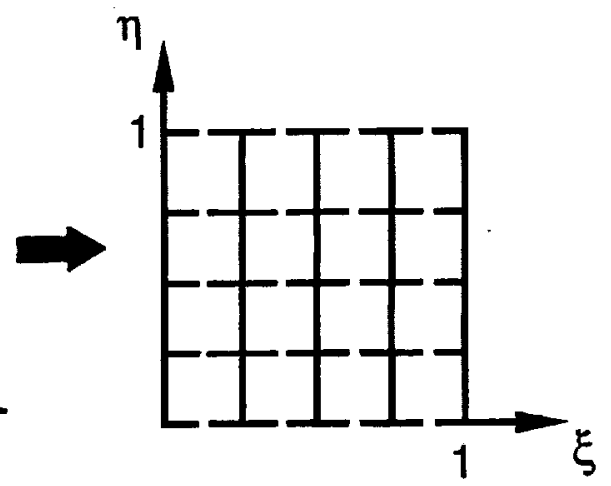

Figure 3.-Diagram of the embedded constraint curves in the parametric cordinate system.

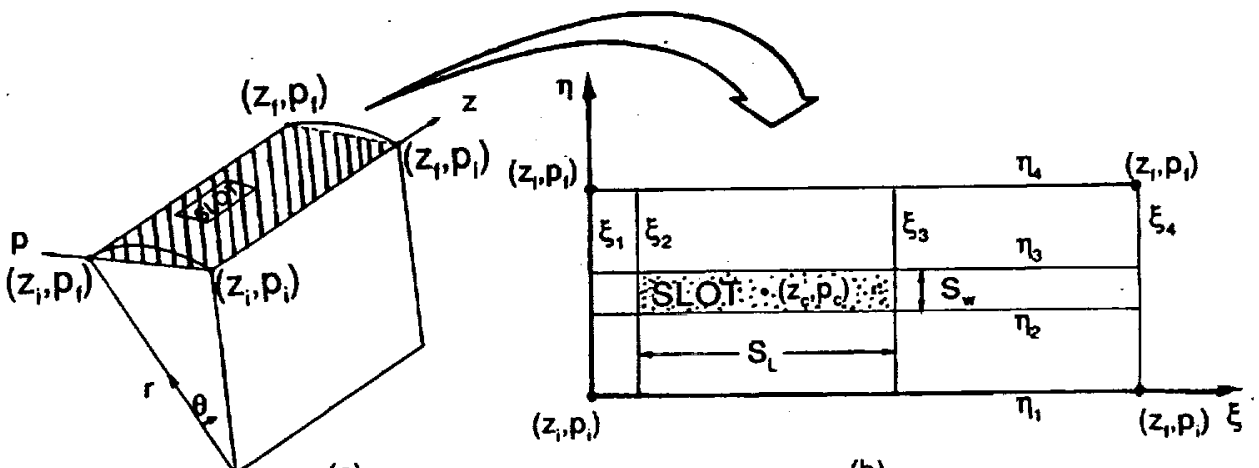

(a)

(b)

Figure 4.-The z-p projection plane and the embedded constraint curves showing the location and size of the slot. 


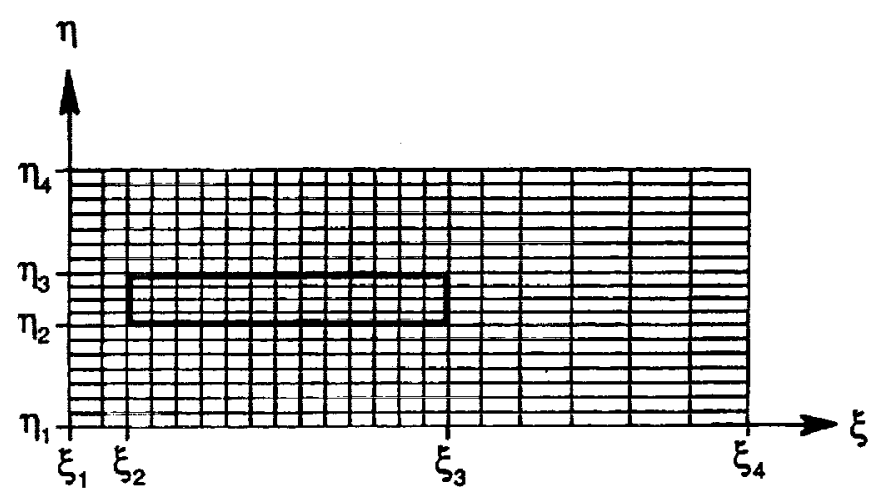

Figure 5. - The z-p plane grid.

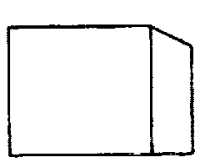

(a) RB/Convergence Sections

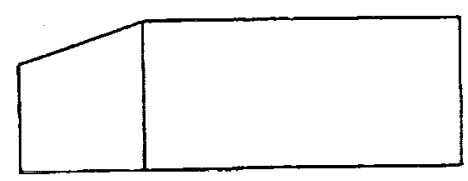

(b) Divergence/LC Sections

Figure 7.-Diagrams of the RB/convergence sections at the divergence $\mathrm{LC}$ section constraint curves.

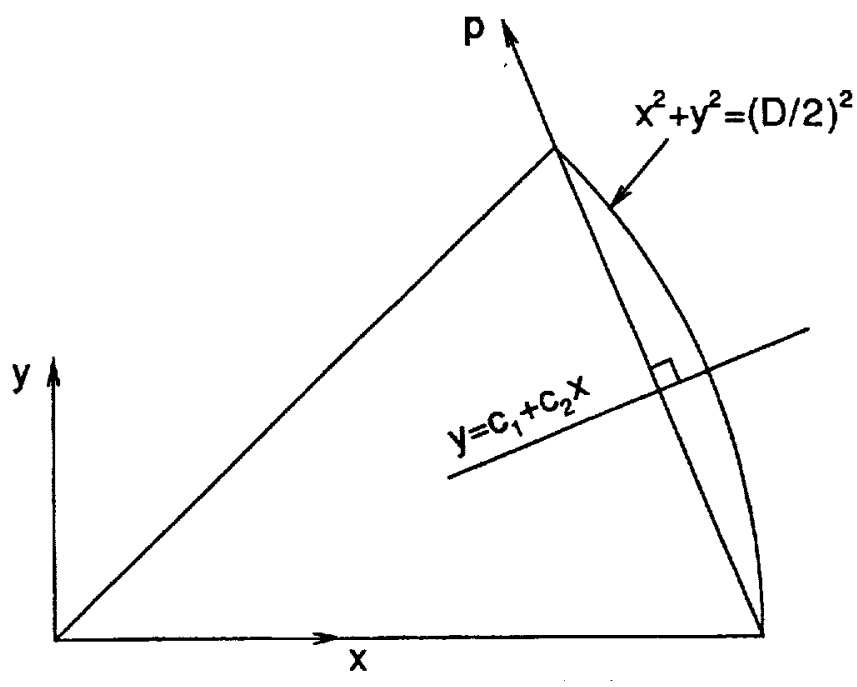

Figure 6.-Schematic of the inverse projection.

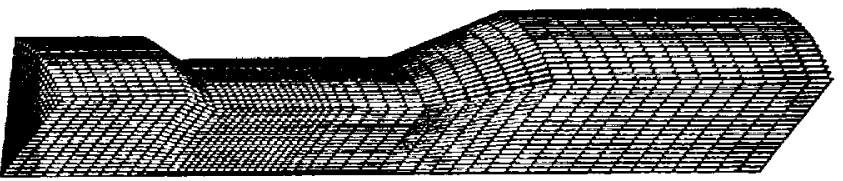

Figure 8.-Prospect view of the grid system before twisting.
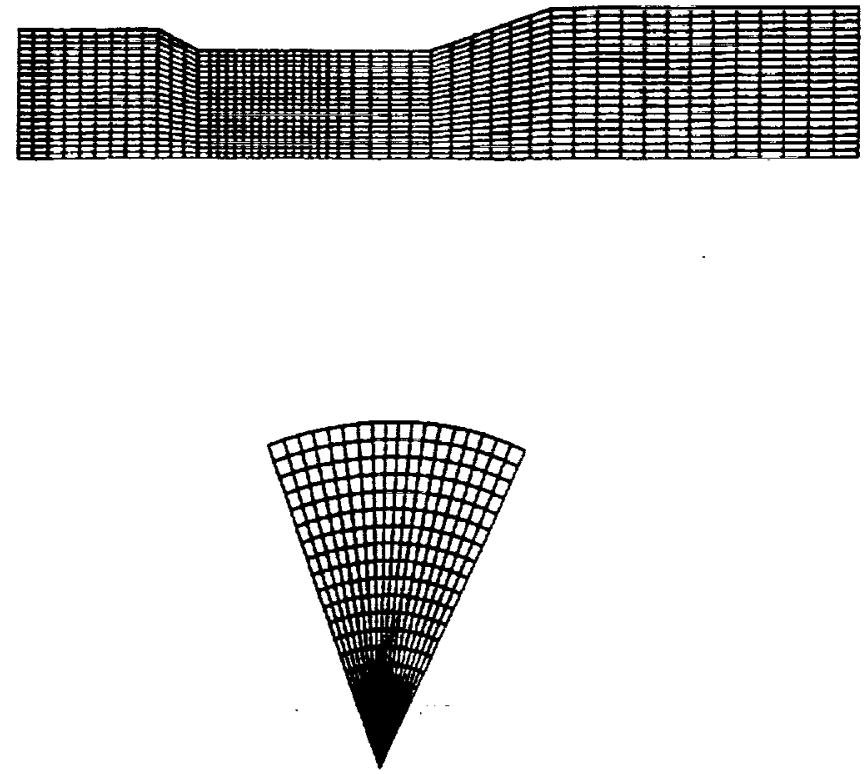

Figure 9.-Cross-sectional views of the grid. 


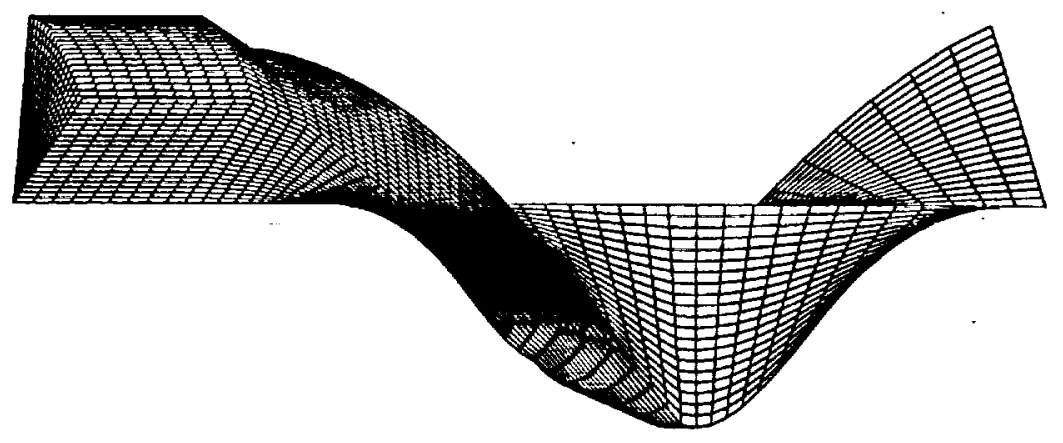

Figure 10.-Perspective view of the grid system after twisting.
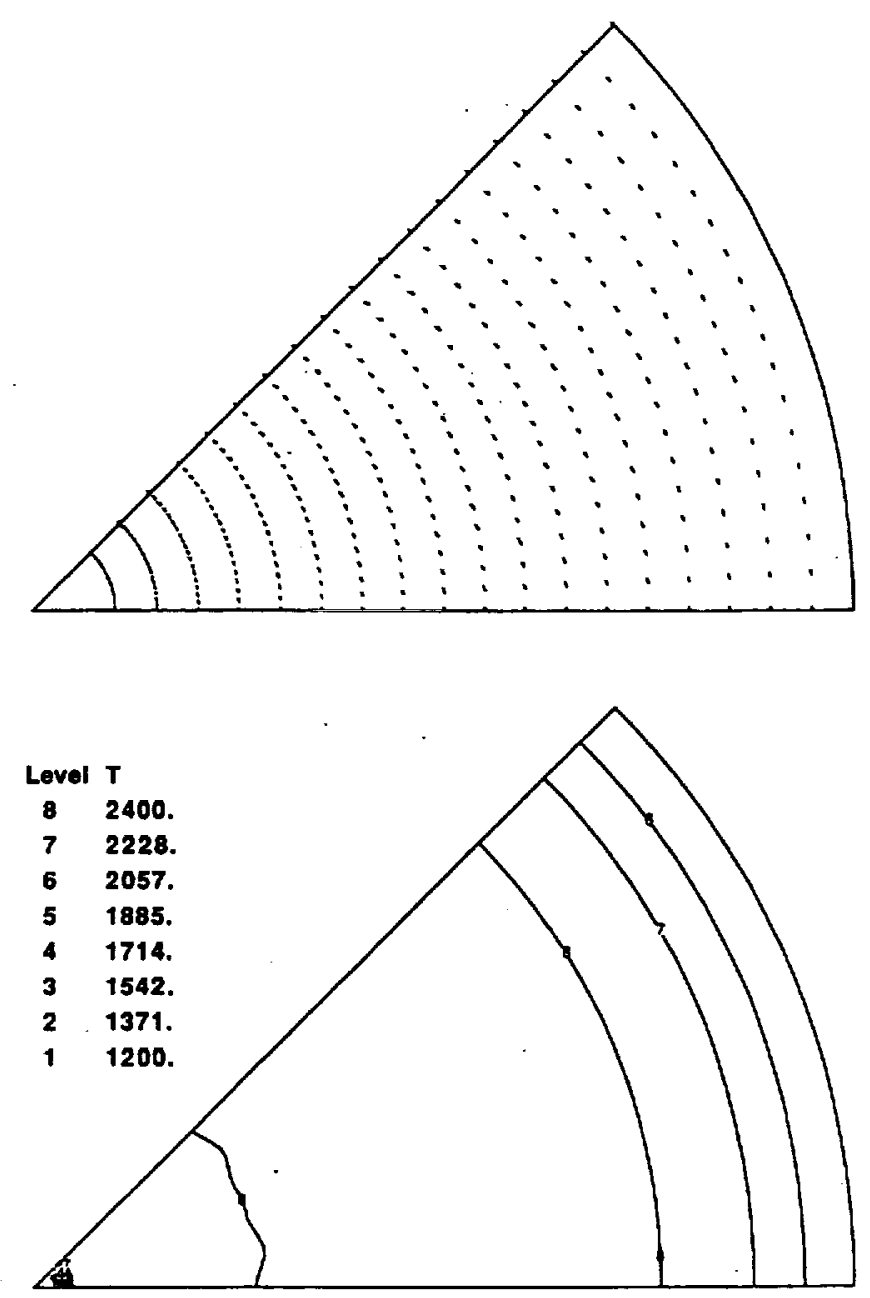

Figure 11.-Velocity vectors and isotherms a the inlet. 


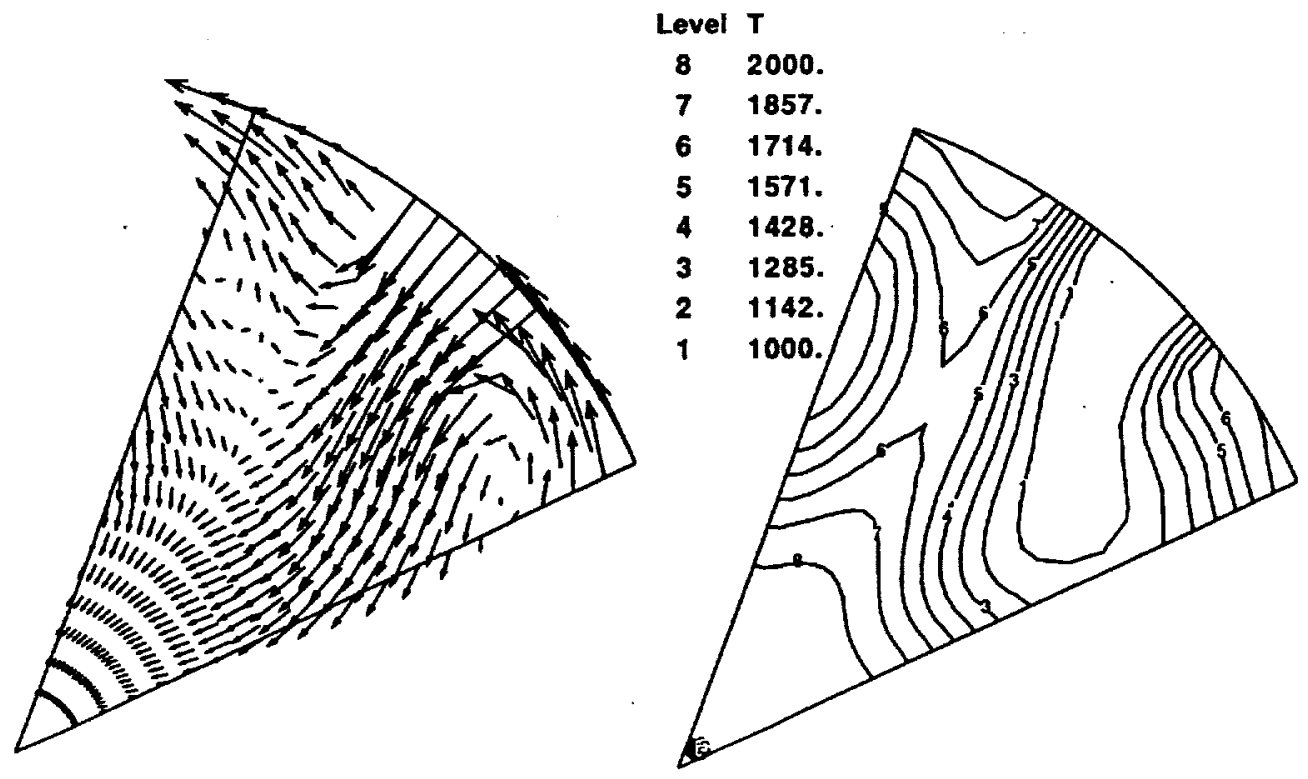

Figure 12.-Velocity vectors and isotherms at the center plane of the slot.
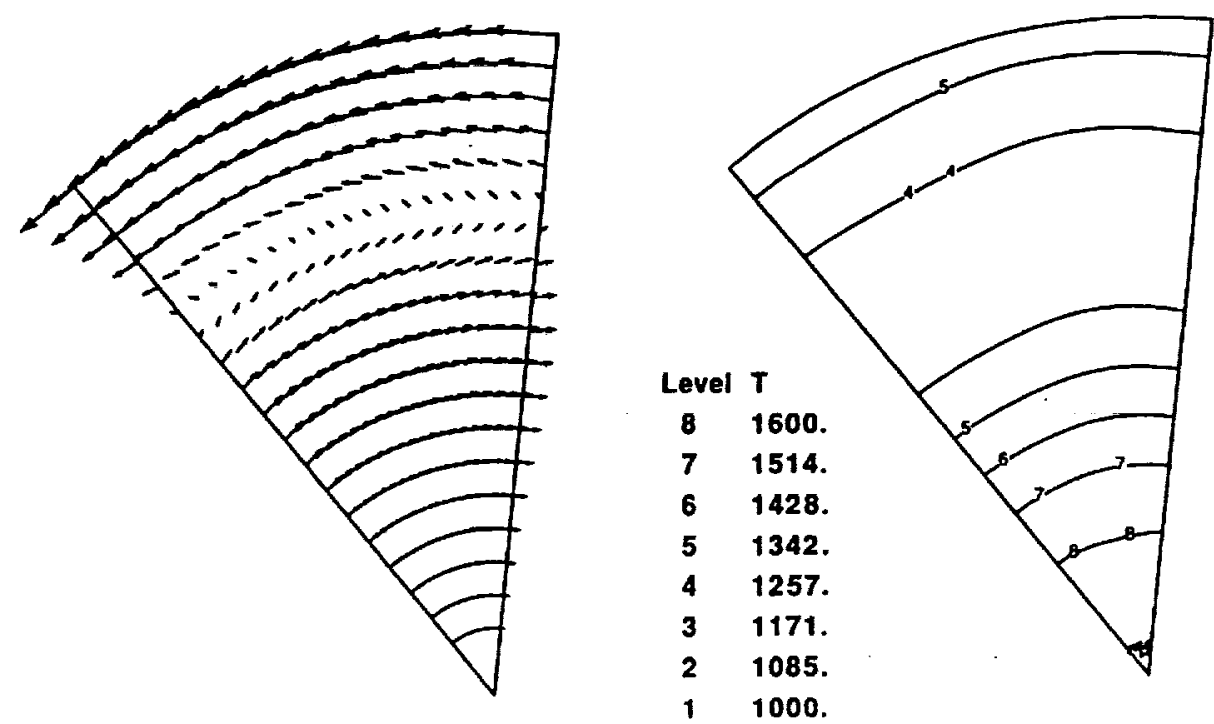

Figure 13.-Velocity vectors and isotherms at 0.991 in. downstream of the slot center. 

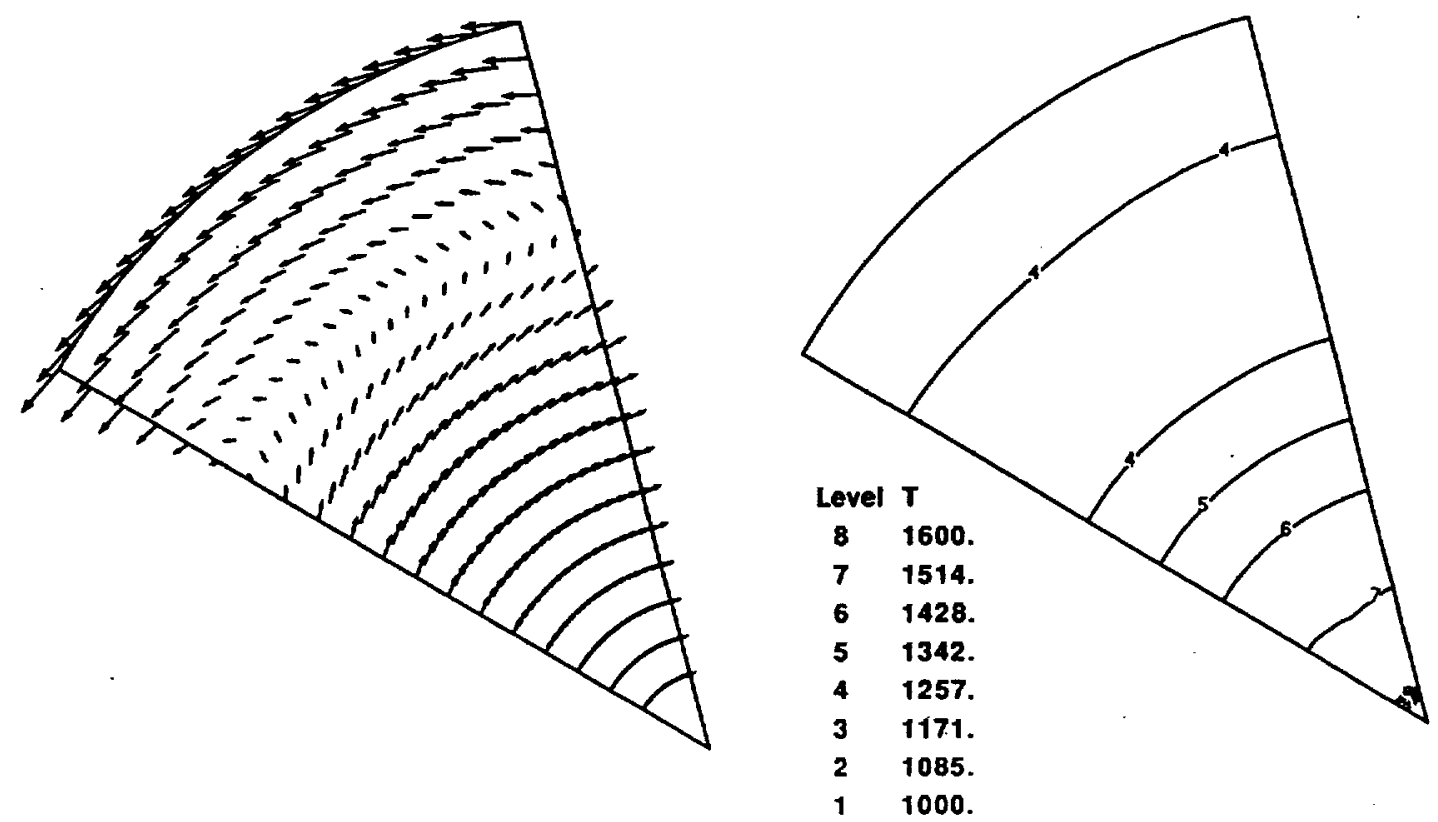

Figure 14.-Velocity vectors and isotherms at the beginning of the divergence section. 

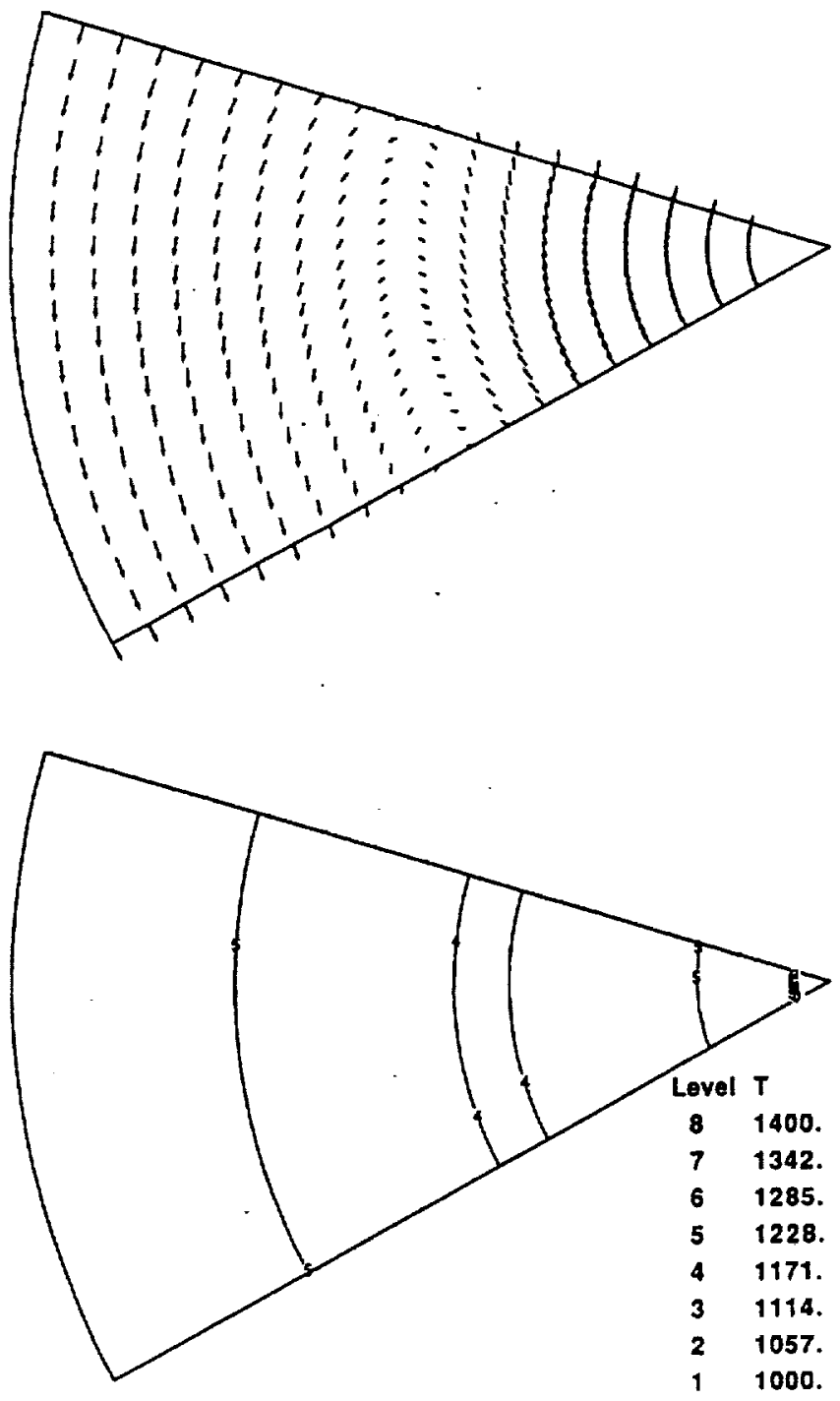

Figure 15.-Velocity vectors and isotherms at the end of the divergence section. 


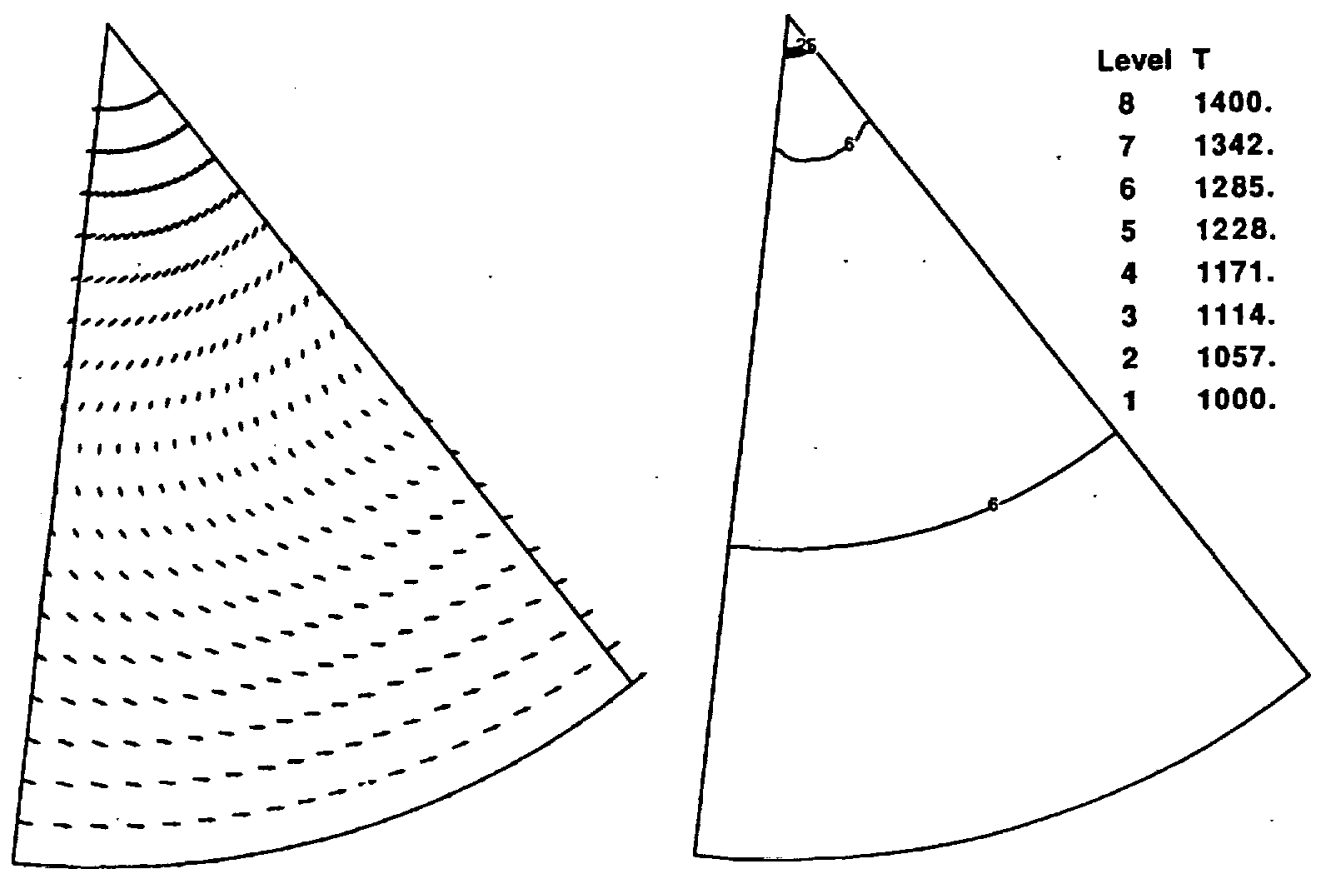

Figure 16. - Velocity vectors and isotherms at the outlet.

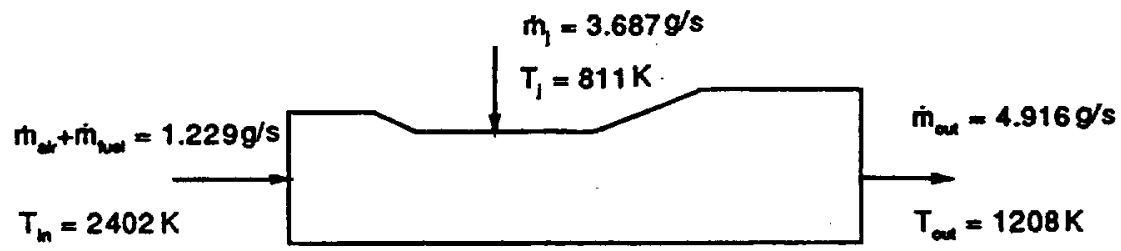

Figure 17.-A control volume used to estimate the equilibrium temperature by energy balance.

23 
Public reporting burden lor this collection of intormation is estimated to average i hour per response. including the time for reviewing instructions. searching existing data sources, gathering and maintaining the data needed. and completing and reviewing the collection of information. Send comments regarding this burden estimate or any other aspect of this collection of information, including suggestions tor reducing this burden, to Washington Headquarters Services, Directorate for Information Operations and Reports. 1215 Jefferson Davis Highway. Suite 1204. Avlington. VA 22202-4302, and to the Otfice of Management and Budget, Paperwork Reduction Project (0704-0188), Washington, DC 20503.

\begin{tabular}{|l|c|c|}
\hline 1. AGENCY USE ONLY (Leave blank) & $\begin{array}{r}\text { 2. REPOAT DATE } \\
\text { March } 1993\end{array}$ & $\begin{array}{r}\text { 3. AEPORT TYPE AND DATES COVERED } \\
\text { Final Contractor Report }\end{array}$ \\
\hline
\end{tabular}

4. TITLE AND SUBTTRE

5. FUNDING NUMBERS

A Three-Dimensional Algebraic Grid Generation Scheme for Gas Turbine Combustors With Inclined Slots

WU-537-02-20

G-NAG3-1109

6. AUTHOR(S)

S.L. Yang, M.C. Cline, R. Chen, and Y.L. Chang

7. PERforming organization Name(S) AND ADdResS(ES)

Michigan Technological University

ME-EM Department

Houghton, Michigan 49931

8. PERFORMING ORGANIZATION REPORT NUMBER

E-7674

9. SPONSORING/MONTTORING AGENCY NAMES(S) AND ADDRESS(ES)

10. SPONSORINGMONITORING AGENCY REPORT NUMBER

National Aeronautics and Space Administration

Lewis Research Center

Cleveland, Ohio 44135-3191

NASA CR-191095

11. SUPPLEMENTARY NOTES

Project Manager, Krishna P. Kundu, Propulsion Systems Division, (216) 433-3939.

12a. DISTRIBUTION/AVAILABILTY STATEMENT

12b. DISTRIBUTION CODE

Unclassified - Unlimited

Subject Categories 05 and 34

13. ABSTAACT (Maximum 200 words)

A 3D algebraic grid generation scheme is presented for generating the grid points inside gas turbine combustors with inclined slots. The scheme is based on the 2D transfinite interpolation method. Since the scheme is a 2D approach, it is very efficient and can easily be extended to gas turbine combustors with either dilution hole or slot configurations. To demonstrate the feasibility and the usefulness of the technique, a numerical study of the quick-quench/lean-combustion (QQ/LC) zones of a staged turbine combustor is given. Preliminary results illustrate some of the major features of the flow and temperature fields in the $Q Q / L C$ zones. Formation of co- and counter-rotating bulk flow and sandwiched-ringshape temperature fields can be observed clearly, and the resulting patterns are consistent with experimental observations typical of the confined slanted jet-in-cross flow. Numerical solutions show the method to be an efficient and reliable tool for generating computational grids for analyzing gas turbine combustors with slanted slots.

\begin{tabular}{|l|l|}
\hline 14. SUBJECT TERMS \\
\hline $\begin{array}{c}\text { 17. SECURTY CLASSIFICATION } \\
\text { OF REPORT } \\
\text { Unclassified }\end{array}$ & $\begin{array}{c}\text { 18. SECURTY CLASSIFICATION } \\
\text { OF THIS PAGE } \\
\text { Unclassified }\end{array}$ \\
\hline
\end{tabular}

19. SECURTY CLASSIFICATION
OF ABSTRACT
Unclassified

Standard Form 298 (Rev. 2-89)

Prescribed by ANSI Std. Z39-18 298-102 